\title{
Surgical Outcomes in Patients With Centrally Located Non-small Cell Lung Cancer
}

\author{
TAKUMA TSUKIOKA, NOBUHIRO IZUMI, HIROAKI KOMATSU, HIDETOSHI INOUE, \\ YUMI MATSUDA, RYUICHI ITO, TAKUYA KIMURA and NORITOSHI NISHIYAMA
}

Department of Thoracic Surgery, Osaka City University, Osaka, Japan

\begin{abstract}
Background/Aim: Identification of prognostic factors is helpful in selecting optimal treatment for centrallylocated non-small cell lung cancer (NSCLC). This study aimed to detect prognostic factors in patients with centrallylocated NSCLC. Patients and Methods: NSCLCs in the hilar area requiring pneumonectomy or sleeve lobectomy for complete removal are defined as centrally-located NSCLCS. We retrospectively investigated the clinical courses of 45 patients with such lesions. Results: Sleeve lobectomies were performed on 33 patients and pneumonectomies on 12. Three and five-year survival rates were $72 \%$ and $62 \%$, respectively. Presence of comorbidities $(p=0.013)$, severe symptoms $(p=0.001)$, high white cell count $(p=0.001)$, and pathological T3-4 stage $(p=0.004)$ were identified as independent predictors of poor prognosis. Operative procedures did not correlate with outcomes $(p=0.722)$. Conclusion: Presence of comorbidities, severe symptoms, high white cell counts, and pathological $T$ stage are independent predictors of poor prognosis. These data can contribute in selecting appropriate treatments for such lesions.
\end{abstract}

Invasive procedures, such as pneumonectomy or sleeve lobectomy, are required to achieve complete resection of centrally-located primary lung cancer. Appropriate operative procedures and surgical outcomes for patients with various stages of lung cancer have been investigated (1-4). However, clinicopathological features differ between peripherally and centrally-located primary lung cancers, including both adenocarcinomas and squamous cell carcinomas $(5,6)$.

This article is freely accessible online.

Correspondence to: Takuma Tsukioka, Department of Thoracic Surgery, Osaka City University, 1-4-3 Asahimachi, Abeno-ku, Osaka 545-8585, Japan. Tel: +81 666453841, Fax: +81 666466057, e-mail:m1156870@med.osaka-cu.ac.jp

Key Words: Centrally located lung cancer, sleeve lobectomy, pneumonectomy, prognostic factor.
Identification of prognostic factors is helpful in selecting appropriate treatment for centrally-located lung cancer patients. In this study, we investigated surgical outcomes and identified predictors of prognosis in patients with completely resected, centrally-located, primary lung cancers.

\section{Patients and Methods}

Primary lung cancer located in the hilar area that requires pneumonectomy or sleeve lobectomy for complete removal is defined as centrally-located lung cancer. In this study, we retrospectively investigated the clinical courses of 45 patients with centrally-located non-small cell lung cancers who had undergone surgical treatment at our institute between January 2011 and December 2018. Lung cancers requiring pneumonectomy or sleeve lobectomy to remove hilar lymph nodes harboring metastases were excluded. Right lower sleeve lobectomies were performed to avoid middle and lower bilobectomies. Thus, patients who had undergone right lower sleeve lobectomy were excluded. Before surgery, all patients provided informed consent for the use of their examination outcomes and data in clinical studies. The local institutional ethics committee approved this study (Approval no. 4403; approval date, 3 October 2019).

Patients with centrally-located lung cancers commonly have symptoms, such as cough, hemoptysis and fever, at the time of diagnosis. In this study, symptoms other than cough were defined as severe symptoms. Comorbidities were defined as disorders being treated at the time of diagnosis of a centrally-located lung cancer.

Mediastinal lymph nodes with a short axis of $>10 \mathrm{~mm}$ on enhanced computed tomography (CT) were diagnosed as clinically positive for metastasis. Our criteria for surgical resection were the absence of distant metastasis, no cancer cell-positive pleural or pericardial effusion, no $\mathrm{N} 2$ disease at two or more mediastinal levels, no bulky $\mathrm{N} 2$ disease, no N3 disease, and a predicted postoperative percent of vital capacity of more than $40 \%$. Patients with T4 lung cancer with N0 or N1 nodal extension and tumors that could be completely removed were considered candidates for surgery. Sleeve lobectomy was performed if anatomically appropriate. Bronchial stumps were usually confirmed as free of cancer cell infiltration by intraoperative pathological examination.

Induction chemoradiotherapy with platinum-based doublet and concurrent radiotherapy (40 Gy) was generally planned for patients with enlarged, but completely removable, N2 lymph node metastasis; however, it was not mandatory for all patients with N2 lymph node metastasis. Patients with pathological stage II and III 
Table I. Patient characteristics.

\begin{tabular}{|c|c|c|}
\hline \multicolumn{2}{|l|}{ Characteristic } & \multirow{2}{*}{$\begin{array}{c}\mathrm{N}=45 \\
70(33-83)\end{array}$} \\
\hline Age (years) & & \\
\hline Gender & Male/Female & $35 / 10$ \\
\hline Smorking history & Yes/No & $43 / 2$ \\
\hline \multirow[t]{6}{*}{ Reasons to diagnosis } & Symptom* & 35 \\
\hline & Cough & 14 \\
\hline & Hemosputum & 14 \\
\hline & Fever up & 13 \\
\hline & Examination for other diseas & 9 \\
\hline & Cancer screaning & 1 \\
\hline \multirow[t]{5}{*}{ Comorbidities** } & Cardiovascular disease & 19 \\
\hline & Other organ malignant tumor & r** 5 \\
\hline & Diabetes melitus & 8 \\
\hline & Liver disease & 5 \\
\hline & Cerebrovascular disease & 5 \\
\hline Clinical $\mathrm{T}$ factor & $1 / 2 / 3 / 4$ & $5 / 18 / 13 / 9$ \\
\hline Clinical $\mathrm{N}$ factor & $0 / 1 / 2$ & $12 / 27 / 6$ \\
\hline Clinical Stage & $\mathrm{I} / \mathrm{II} / \mathrm{III}$ & $6 / 17 / 22$ \\
\hline \multicolumn{3}{|l|}{ Surgical procedure } \\
\hline \multirow[t]{4}{*}{ Right } & Pneumonectomy & 4 \\
\hline & Upper & 10 \\
\hline & Middle and lower & 2 \\
\hline & Upper and middle & 1 \\
\hline \multirow[t]{5}{*}{ Left } & Pneumonectomy & 8 \\
\hline & Upper & 7 \\
\hline & Lower & 6 \\
\hline & Lower and lingular division & 4 \\
\hline & Upper and segment 6 & 3 \\
\hline \multirow[t]{3}{*}{ Histological subtypes } & Squamous cell carcinoma & 39 \\
\hline & Adenocarcinoma & 5 \\
\hline & Pleomorphic carcinoma & 1 \\
\hline \multirow[t]{11}{*}{ Adverse events*** } & Pneumonia & 6 \\
\hline & Pleural effusion & 6 \\
\hline & Broncho-pleural fistula & 2 \\
\hline & Empyema & 2 \\
\hline & Prolonged air leakage & 1 \\
\hline & Brain infarction & 1 \\
\hline & Arrythmis & 1 \\
\hline & Recurent nerve palsy & 1 \\
\hline & Paralytic ileus & 1 \\
\hline & Surgical site infection & 1 \\
\hline & Chylothorax & 1 \\
\hline Pathological T factor**** & $1 / 2 / 3 / 4$ & $6 / 14 / 13 / 10$ \\
\hline Patholgical N factor**** & $0 / 1 / 2$ & $15 / 21 / 8$ \\
\hline Pathological stage**** & $\mathrm{I} / \mathrm{II} / \mathrm{III}$ & $6 / 20 / 18$ \\
\hline Adjuvant chemotherapy & & $15(33 \%)$ \\
\hline
\end{tabular}

Values are medians (range). $*$ Some patients have more than two symptoms. **Some patients have more than two comorbiditires. ***Some patients have more than two adverse events. ****A patient without residual tumor after induction treatment was excluded.

lung cancer had adjuvant platinum-based doublet chemotherapy whereas those with stage I lung cancer received oral-tegafur adjuvant chemotherapy. We did not set criteria for omitting adjuvant treatment, such treatment being initiated at the discretion of the physician in charge of each case.

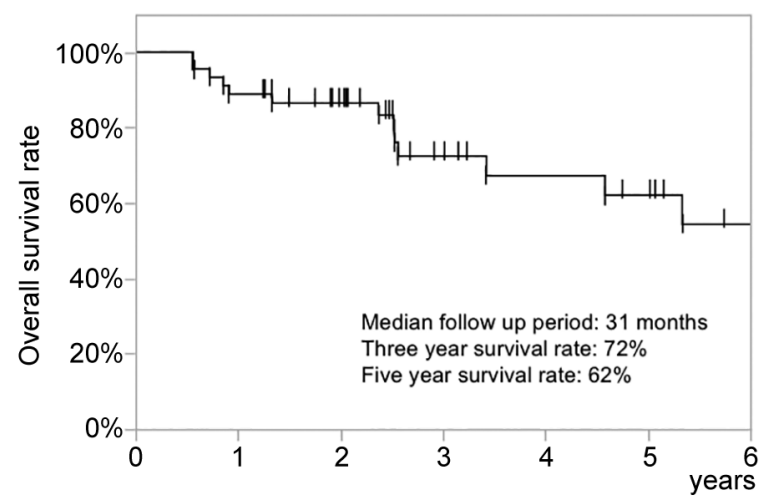

$\begin{array}{llllllll}\text { No. at risk } & 45 & 41 & 33 & 19 & 14 & 12 & 7\end{array}$

Figure 1. Overall survival of 45 patients with centrally-located nonsmall cell lung cancer.

After discharge, all patients had follow-up chest radiographs and measurement of tumor markers every 2-4 months and CT scans at 6 months and every year thereafter. The last follow-up review was conducted on 31 March 2021.

The median value was used as the cutoff value for age. The cutoff value for white blood cell count was in accordance with the institutional cutoff value. Overall survival was analyzed using the Kaplan-Meier method, differences being assessed using the log-rank test. Independent risk factors associated with survival were calculated using a Cox proportional hazard model. A $p$-value of $<0.05$ was considered to denote statistical significance. Statistical analysis was performed using JMP 10 software (SAS Institute, Cary, NC, USA).

\section{Results}

Table I shows the patient characteristics. Thirty-five patients had tumor-related symptoms. Severe symptoms, namely haemoptysis and fever, were present in 14 and 13 patients, respectively. Thirty-three patients underwent sleeve lobectomy and 12 underwent pneumonectomy, right-sided in four and left-sided in eight. The commonest histological subtype was squamous cell carcinoma. Two bronchopleural fistulas occurred, one after left upper sleeve lobectomy and the other after left lower plus lingual segment sleeve lobectomy. Five patients had induction treatment with platinum doublet plus concurrent radiotherapy (40 Gy). Fifteen patients $(33 \%)$ received adjuvant chemotherapy.

The median duration of follow-up was 31 months. There were no treatment-related deaths in this study. Figure 1 shows the overall survival curve for all study patients. The three and five-year survival rates were $72 \%$ and $62 \%$, respectively. Figure 2 shows the overall survival curves according to selected clinical factors. There were significant differences in survival rate according to preoperative white cell count and pathological $\mathrm{T}$ stage. 
a

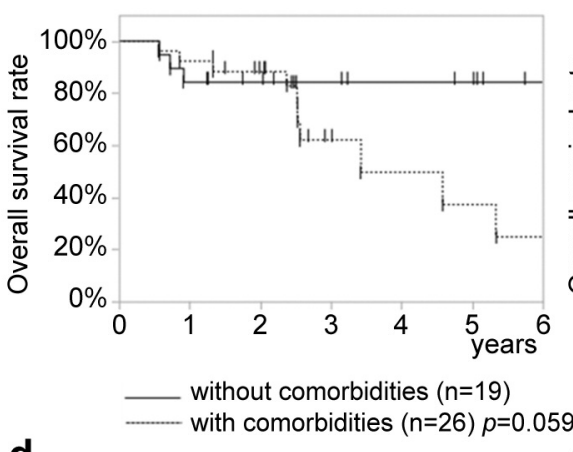

d

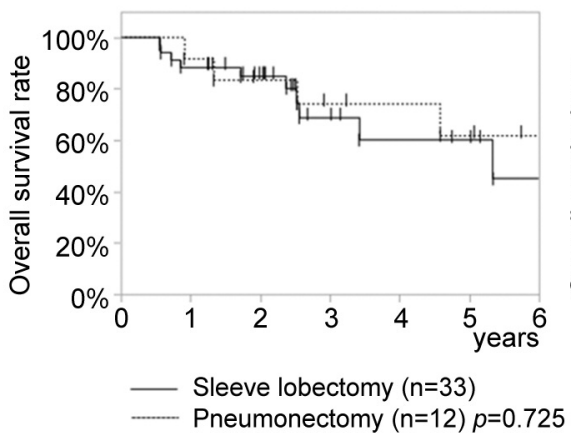

b
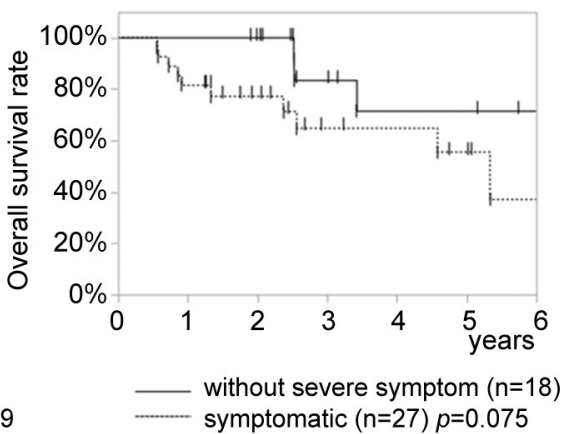

\section{e}

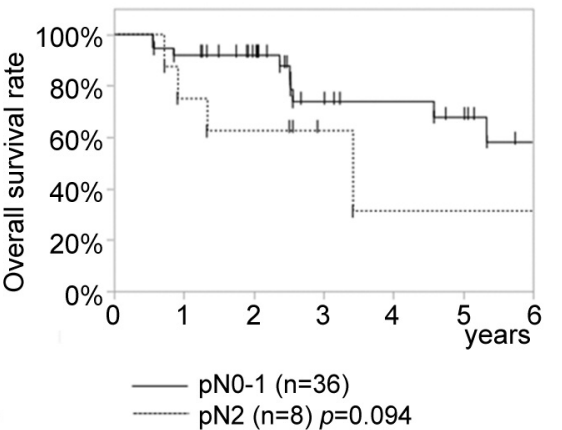

C

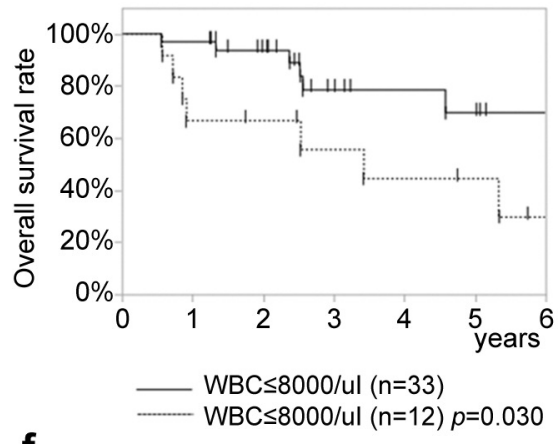

f

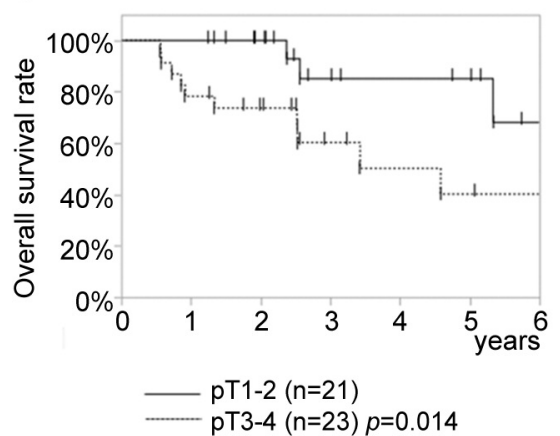

Figure 2. Overall survival according to the presence of comorbidities (a), severe symptoms (b), white cell counts (c), type of surgical procedure (d), pathological nodal status (e), and pathological $T$ stage $(f)$.

Table II shows the univariate and multivariate analysis for predictors of poor prognosis. Multivariate analysis identified the presence of comorbidities, severe symptoms, high preoperative white cell counts, and pathological $\mathrm{T}$ stage as significant independent predictors of poor prognosis. In this study, 26 patients had comorbidities at the time of diagnosis of lung cancer, seven of whom died of causes other than primary lung cancer during the study period.

No patient had local recurrence in the hilar area during the study period. Type of surgical procedure did not correlate with postoperative outcomes (Figure 2, Table II). Table III shows a comparison of patient characteristics and clinical courses according to surgical procedure. Advanced lung cancer required pneumonectomy to achieve complete resection. Patients who underwent pneumonectomy had favorable forced expiratory volumes in 1 second. Adverse events were rarely observed after pneumonectomy.

\section{Discussion}

In this study, we investigated postoperative outcomes in patients with centrally-located lung cancer. We found that the presence of comorbidities or severe symptoms, high preoperative white cell counts, and pathological T stage were independent predictors of poor prognosis. This is a meaningful study and our results can be helpful in selecting optimal treatment for centrally-located NSCLC. It appears that patients with $\mathrm{pN} 2$ disease had poor outcomes (Figure $2 \mathrm{e}$ ); however, because this study included only eight patients with pN2 disease, this was not identified as a statistically significant predictor of poor prognosis.

The presence of comorbidities is a significant predictor of poor prognosis. Seven of 26 patients with comorbidities died of causes other than lung cancer during the study period. Deaths for other reasons have never been observed in patients without comorbidities. Hristov et al. reported that the presence of comorbidities is a significant risk factor for non-cancer-specific mortality after lung cancer surgery in patients aged 65 years (7). Invasive thoracotomy is also reportedly associated with non-cancer-specific mortality in older patients, especially those with comorbidities. It is important to consider these data when selecting treatment for centrally-located lung cancer patients.

We found that patients with severe symptoms, such as hemoptysis and fever, had poor prognoses. A high white cell count was also a predictor of poor prognosis. Obstructive pneumonia caused by a centrally-located lung cancer is the major reason for fever and a severe inflammatory response. Neutrophils can facilitate metastatic spread (8). Detection of a centrally-located lung cancer before development of an 
in vivo $35: 2815-2820(2021)$

Table II. Results of univariate and multivariate analyses of overall survival.

\begin{tabular}{|c|c|c|c|c|c|c|c|c|}
\hline & & \multirow[b]{2}{*}{$\mathrm{n}$} & \multicolumn{3}{|c|}{ Univariate analysis } & \multicolumn{3}{|c|}{ Multivariate analysis } \\
\hline & & & HR & $95 \% \mathrm{CI}$ & $p$-Value & HR & $95 \% \mathrm{CI}$ & $p$-Value \\
\hline \multirow[t]{2}{*}{ Age (years) } & $\leq 70$ & 23 & 1.0 & $0.49-4.69$ & 0.520 & & & \\
\hline & $>70$ & 22 & 1.4 & & & & & \\
\hline \multirow[t]{2}{*}{ Comorbidities } & No & 19 & 1.0 & $0.07-1.01$ & 0.052 & 1.0 & $0.05-0.73$ & 0.013 \\
\hline & Yes & 26 & 3.3 & & & & 4.5 & \\
\hline \multirow{2}{*}{ Sever symptom* } & No & 18 & 1.0 & $0.07-1.07$ & 0.066 & 1.0 & $0.02--0.45$ & 0.001 \\
\hline & Yes & 27 & 3.1 & & & & 8.9 & \\
\hline \multirow[t]{2}{*}{ White blood cell } & $\leq 8,000 / \mu \mathrm{l}$ & 33 & 1.0 & $0.10-0.96$ & 0.030 & 1.0 & $0.04-0.54$ & 0.004 \\
\hline & $>8,000 / \mu \mathrm{l}$ & 12 & 3.2 & & & & 6.6 & \\
\hline \multirow[t]{2}{*}{$\% \mathrm{VC}$} & $<80 \%$ & 7 & 1.0 & $0.03-3.10$ & 0.594 & & & \\
\hline & $\geq 80 \%$ & 38 & 0.6 & & & & & \\
\hline \multirow[t]{2}{*}{ FEV1.0\% } & $<70 \%$ & 24 & 1.0 & $0.35-3.11$ & 0.894 & & & \\
\hline & $\geq 70 \%$ & 21 & 0.9 & & & & & \\
\hline \multirow{2}{*}{ Surgical methods } & Sleeve lobectomy & 33 & 1.0 & $0.40-4.62$ & 0.722 & & & \\
\hline & Pneumonectomy & 12 & 1.2 & & & & & \\
\hline \multirow[t]{2}{*}{$\begin{array}{l}\text { Histological } \\
\text { subtypes }\end{array}$} & $\begin{array}{l}\text { Squamous cell } \\
\text { carcinoma }\end{array}$ & 39 & 1.0 & $0.33-31.0$ & 0.585 & & & \\
\hline & Others & 6 & 0.6 & & & & & \\
\hline Pathological & $1 / 2$ & 21 & 1.0 & $0.05-0.75$ & 0.013 & 1.0 & $0.02-0.42$ & 0.001 \\
\hline $\mathrm{T}$ factor** & $3 / 4$ & 23 & 4.3 & & & 9.8 & & \\
\hline Pathological & $0 / 1$ & 36 & 1.0 & $0.13-1.33$ & 0.129 & & & \\
\hline $\mathrm{N}$ factor** & 2 & 8 & 2.5 & & & & & \\
\hline \multirow{2}{*}{$\begin{array}{l}\text { Adjuvant } \\
\text { chemotherapy }\end{array}$} & No & 30 & 1.0 & $0.37-4.28$ & 0.806 & & & \\
\hline & Yes & 15 & 0.9 & & & & & \\
\hline
\end{tabular}

HR, Hazard ratio; CI, confidence interval; \%VC, percent of vital capacity; FEV1.0\%, forced expiratory volume in 1 second as a percent of forced vital capacity. *Sever symtoms included hemosputum and fever up. **A patient without residual tumor after induction treatment was excluded.

inflammatory response may contribute to improving prognosis. Ten of our patients were asymptomatic, lung cancer was diagnosed by screening or examination for another reason, whereas the other patients had symptoms at the time of diagnosis. Many of our study patients had comorbidities. It has been reported that lung cancer patients with pre-existing comorbidities visit their physicians more frequently (9). Thus, early diagnosis of lung cancer is commonly associated with the presence of comorbid conditions. Because centrally-located lung tumors are often concealed behind mediastinal or vessel shadows, they are rarely diagnosed accidentally by chest radiography. Deep learning has demonstrated reliable potential for detection of lung cancer in chest radiographs $(10,11)$. Artificial intelligence may thus contribute to early detection of centrally-located lung cancers.

Several groups have reported poor prognosis after pneumonectomy $(12,13)$. Emmanouilides et al. reported reimplantation techniques to avoid pneumonectomy in patients with centrally-located lung cancer (14). In the current study, although patients with more advanced lung cancer underwent pneumonectomy, their outcomes were similar to those of patients who underwent sleeve lobectomy. Pneumonectomy is considered to be essential to achieving complete resection in patients with advanced centrally-located lung cancer. Provided patients are selected appropriately, for example by including only those with sufficient respiratory function, post-pneumonectomy adverse events can be minimized. However, patients who undergo pneumonectomy are less likely to subsequently receive adjuvant chemotherapy, generally because of their poor postoperative performance status. Because pneumonectomy reliably achieves local control, it has been suggested that adjuvant therapies are crucially important for postoperative outcomes. Tolerance to adjuvant treatment should be carefully considered. Use of immune checkpoint inhibitors has been approved for treatment of advanced and metastatic solid tumors of many types. Nonetheless, the only role they have in an adjuvant setting is for surgically resected melanomas (15). No benefit has yet been identified for adjuvant immunotherapy for lung cancer patients. After validation studies, adjuvant immunotherapy is considered to be essential for centrallylocated lung cancer patients.

This study had certain limitations. First, it was a small retrospective study. Accumulation of data from more patients 
Table III. Comparison of patient charadteristics according to surgical procedure.

\begin{tabular}{|c|c|c|c|c|}
\hline & & Sleeve lobectomy $(n=33)$ & Pneumonectomy $(\mathrm{n}=12)$ & $p$-Value \\
\hline Age & & $71(33-83)$ & $66(53-78)$ & 0.126 \\
\hline Body mass index & & $22.8(15.8-34.4)$ & $21.1(18.1-29.8)$ & 0.299 \\
\hline Cormobidities & & $19(58 \%)$ & $7(58 \%)$ & 0.964 \\
\hline$\% \mathrm{VC}(\%)$ & & $97(73-139)$ & $92(79-127)$ & 0.837 \\
\hline$\%$ FEV1.0 (\%) & & $80(48-153)$ & $100(70-140)$ & 0.001 \\
\hline$\% \operatorname{DLCO}(\%)$ & & $86(50-149)$ & $89(50-125)$ & 0.521 \\
\hline \multirow[t]{2}{*}{$\mathrm{pT}^{*}$} & $1 / 2$ & 19 & 2 & 0.024 \\
\hline & $3 / 4$ & 14 & 9 & \\
\hline \multirow[t]{2}{*}{$\mathrm{pN}^{*}$} & $0 / 1$ & 29 & 7 & 0.087 \\
\hline & 2 & $4(12 \%)$ & $4(33 \%)$ & \\
\hline \multirow[t]{2}{*}{ p Stage* } & $\mathrm{I} / \mathrm{II}$ & 21 & 5 & 0.291 \\
\hline & III & $12(36 \%)$ & $6(50 \%)$ & \\
\hline Adverse events & & $11(33 \%)$ & $1(8 \%)$ & 0.069 \\
\hline Pneumonia & & 6 & 1 & \\
\hline Broncho-pleural fistula & & 2 & 0 & \\
\hline Empyema & & 4 & 0 & \\
\hline \multirow[t]{2}{*}{ Adjuvant chemotherapy } & Yes & $12(36 \%)$ & $3(25 \%)$ & 0.467 \\
\hline & No & 21 & 9 & \\
\hline
\end{tabular}

Values are median (range). \% VC, percent of vital capacity; \%FEV1.0, percent of forced expiratory volume in 1 second; \%DLCO, percent of diffusing capacity of lung for carbon monoxide. *A patient without residual tumor after induction treatment was excluded.

and further analyses are now ongoing. Second, treatments were selected at the discretion of the physician in charge of each case. Selection criteria for surgical procedures and perioperative therapy should be established in further prospective studies. Finally, preoperative examination has not yet been standardized and there were some conflicting clinical and pathological findings. A standard preoperative examination schedule, including positron emission tomography/computed tomography or endobronchial ultrasound-guided biopsy as necessary, should be established to improve the accuracy of staging.

In conclusion, in this study we found that the presence of comorbidities or severe symptoms, high preoperative white cell counts, and pathological $\mathrm{T}$ stage are independent predictors of poor prognosis in centrally-located lung cancer patients. These results may contribute to selection of optimal treatment for centrally-located lung cancer patients.

\section{Conflicts of Interest}

The Authors have no conflicts of interest to declare regarding this study.

\section{Authors' Contributions}

Takuma Tsukioka designed the study, analyzed the data, prepared the figures and wrote original draft. Nobuhiro Izumi and Noritoshi Nishiyama oversaw the study and revised the article. All Authors reviewed the article.

\section{References}

1 Yamaguchi M, Nakagawa K, Suzuki K, Takamochi K, Ito H, Okami J, Aokage K, Shiono S, Yoshioka H, Aoki T, Tsutani Y, Okada M, Watanabe SI and Lung Cancer Surgical Study Group (LCSSG) of the Japan Clinical Oncology Group (JCOG): Surgical challenges in multimodal treatment of N2-stage IIIA non-small cell lung cancer. Jpn J Clin Oncol 51(3): 333-344, 2021. PMID: 33506253. DOI: 10.1093/jjco/hyaa249

2 Watanabe Y, Hattori A, Nojiri S, Matsunaga T, Takamochi K, Oh $\mathrm{S}$ and Suzuki K: Clinical impact of a small component of ground-glass opacity in solid-dominant clinical stage IA nonsmall cell lung cancer. J Thorac Cardiovasc Surg, 2020. PMID: 33516459. DOI: $10.1016 /$ j.jtcvs.2020.12.089

3 Suzuki K, Watanabe SI, Wakabayashi M, Saji H, Aokage K, Moriya Y, Yoshino I, Tsuboi M, Nakamura S, Nakamura K, Mitsudomi T, Asamura H and West Japan Oncology Group and Japan Clinical Oncology Group: A single-arm study of sublobar resection for ground-glass opacity dominant peripheral lung cancer. J Thorac Cardiovasc Surg, 2020. PMID: 33487427. DOI: $10.1016 /$ j.jtcvs.2020.09.146

4 Mimae T, Saji H, Nakamura H, Okumura N, Tsuchida M, Sonobe M, Miyazaki T, Aokage K, Nakao M, Haruki T, Okada M, Suzuki K and Chida M: Survival of octogenarians with earlystage non-small cell lung cancer is comparable between wedge resection and lobectomy/segmentectomy: JACS1303. Ann Surg Oncol, 2021. PMID: 33900499. DOI: 10.1245/s10434-02109835-w

5 Wang Z, Li M, Teng F, Kong L and Yu J: Primary tumor location is an important predictor of survival in pulmonary adenocarcinoma. Cancer Manag Res 11: 2269-2280, 2019. PMID: 30962716. DOI: 10.2147/CMAR.S192828 
6 Lin MW, Huang YL, Yang CY, Kuo SW, Wu CT and Chang YL: The differences in clinicopathologic and prognostic characteristics between surgically resected peripheral and central lung squamous cell carcinoma. Ann Surg Oncol 26(1): 217-229, 2019. PMID: 30456676. DOI: 10.1245/s10434-018-6993-5

7 Hristov B, Eguchi T, Bains S, Dycoco J, Tan KS, Isbell JM, Park BJ, Jones DR and Adusumilli PS: Minimally invasive lobectomy is associated with lower noncancer-specific mortality in elderly patients: A propensity score matched competing risks analysis. Ann Surg 270(6): 1161-1169, 2019. PMID: 29672399. DOI: $10.1097 /$ SLA. 0000000000002772

8 Kos K and de Visser KE: Neutrophils create a fertile soil for metastasis. Cancer Cell 39(3): 301-303, 2021. PMID: 33513347. DOI: 10.1016/j.ccell.2021.01.009

9 Dima S, Chen KH, Wang KJ, Wang KM and Teng NC: Effect of comorbidity on lung cancer diagnosis timing and mortality: A nationwide population-based cohort study in Taiwan. Biomed Res Int 2018: 1252897, 2018. PMID: 30519567. DOI: 10.1155/ 2018/1252897

10 Yoo H, Kim KH, Singh R, Digumarthy SR and Kalra MK: Validation of a deep learning algorithm for the detection of malignant pulmonary nodules in chest radiographs. JAMA Netw Open 3(9): e2017135, 2020. PMID: 32970157. DOI: 10.1001/ jamanetworkopen.2020.17135

11 Armato SG $3^{\text {rd: }}$ Deep learning demonstrates potential for lung cancer detection in chest radiography. Radiology 297(3): $697-$ 698, 2020. PMID: 32965172. DOI: 10.1148/radiol.2020203538
12 Pagès $\mathrm{PB}$, Mordant $\mathrm{P}$, Renaud $\mathrm{S}$, Brouchet $\mathrm{L}$, Thomas PA, Dahan M, Bernard A and Epithor Project (French Society of Thoracic and Cardiovascular Surgery): Sleeve lobectomy may provide better outcomes than pneumonectomy for non-small cell lung cancer. A decade in a nationwide study. J Thorac Cardiovasc Surg 153(1): 184-195.e3, 2017. PMID: 27814899. DOI: $10.1016 /$ j.jtcvs.2016.09.060

13 Abdelsattar ZM, Shen KR, Yendamuri S, Cassivi S, Nichols FC 3rd, Wigle DA, Allen MS and Blackmon SH: Outcomes after sleeve lung resections versus pneumonectomy in the United States. Ann Thorac Surg 104(5): 1656-1664, 2017. PMID: 28935348. DOI: 10.1016/j.athoracsur.2017.05.086

14 Emmanouilides C, Tryfon S, Baka S, Titopoulos H, Dager A and Filippou D: Operation for preservation of lung parenchyma in central lung cancer-in vivo and ex situ reimplantation techniques. Anticancer Res 35(3): 1675-1681, 2015. PMID: 25750327.

15 Moujaess E, Haddad FG, Eid R and Kourie HR: The emerging use of immune checkpoint blockade in the adjuvant setting for solid tumors: a review. Immunotherapy 11(16): 1409-1422, 2019. PMID: 31621445. DOI: 10.2217/imt-2019-0087

Received May 13, 2021

Revised June 2, 2021

Accepted June 3, 2021 